Кулагин Д. А., Качур А. С., Андриенко П. Д. Разработка модели модернизированного частотноуправляемого тягового электропривода со сменным алгоритмом управления дизель-поезда ДЭЛ-02.

Разработана модель системы асинхронного электропривода дизель-поезда с дополнительной внутренней обратной связью по частоте поля двигателя.

Kulagin D. O., Kachur O. S., Andrianko P. D. Development of model modernized frequency guided hauling electromechanic with the variable algorithm of management diesel-locomotiv of DEL-02.

The model of a Diesel train asynchronous electric drive system with additional intrinsic feedback by engine field frequency has been developed.

\title{
Microprocessor Protection Devices: the Present and the Future
}

\author{
The paper presents the analysis of the basic constructive disadvantages of the present day \\ microprocessor-based protective devices (MBR) and offers the basic principles for creating a new \\ $M B R$ that can be used in newly constructed devices.
}

Microprocessor-based protective devices, Relay damages, Relay protection reliability

\section{Introduction}

Electromechanical protective relays of the past generation completely met all the requirements set for protection devices of electrical power equipment for many, many years. In the latest microprocessor-based devices the function of relay protection has been united with functions of other devices: communication and data trans-mission devices, fault recorders, substation logic units, etc. Such multipurpose complexes are compared now to the individual onefunctional electromechanical relays which have been functioning for decades and which are now considered as rather worn out. It is said about advantages of microprocessor relays compared to electromechanical relays as about absolutely obvious fact. What has been overlooked, though, is that these devices perform completely different functions which simply cannot be compared with each other [1]. Specialists of world leading manufactures have published a considerable number of half-advertising articles stressing only the positive qualities of microprocessor-based protective relays (MBR). There are a few publications of certain authors devoted solely to the analysis of problems, connected with transition to MBR although there are many more others. Though the problems connected with MBR expansion are obvious, the fact that their distribution is increasing and that they are replacing electromechanical relays completely is inevitable only because almost all world leading manufacturers have stopped producing electromechanical protective relays. It has happened not because electromechanical relays have insuperable disadvantages of any great importance (they just wore out and have not been improved for the last 30-40 years), but because of the enormous profit gained by MBR producers which is (c) V. I. Gurevich 2010 p. beyond comparison in relation to the manufacture of electromechanical protective relays [1]. As the future of relay protection is inevitably connected with MBR (at least, for complex protection functions), the forecast of ways of development of this equipment is of definite interest.

The analysis of principles structural lacks of MRB of present generation and suggestion is the purpose of this article on creation of MRB of next generation, intended for the again entered new objects.

\section{Modern lines in designing microprocessor protection devices}

1.1. If one considers the «Factor of Unit Functionality» (FUF) parameter-how many functions are there in a single MBR - one can ascertain that this parameter grows year after year. The MBR's physical size remains constant (or even decreases) and but its functionality continually increases. What is the reason of such a growth? In our opinion, there is no objective necessity to increase the FUF, it is only a matter of the competitive activity among MBR producers and their aspiration to excel each other in technological level of produced devices. As the FUF has direct relation to the technical and technological level of the equipment, increasing the FUF is usually associated directly with MBR technological level and capabilities of the manufacturer. Thus, we think, that increasing the FUF in MBR is no more than the means of competitive activity. Is this tendency useful and does it really results in increasing MBR quality? At first sight, yes, because, as it was already mentioned above, FUF increase is provided through the use of more progressive materials, elements and techno- 
logies and is directly associated with MBR technological level increase. However, in practice everything appears to be not so simple. As progress in the sphere of new materials and technologies is in fact not as prompt as MBR producers want it to be, they use any methods to achieve their aim, i. e., to increase the FUF. Already there is a tendency to constantly make the software more and more complicated, to make the interface more intricate, to include huge amounts of functions that are not used in practice. All this makes work with MBR considerably more complicated and raises error probability owing to the «human factor» [1]. Some frequently promoted «outstanding abilities» of MBR, with increased FUF, such as, for example, full internal self-diagnostics, in practice appear to be no more than an advertising gimmick created to justify MBR complication and cost increase. How is it possible to speak about the effi-ciency of self-diagnostics, if it is not able to discover the replacement of a whole printed circuit board of the MBR, not to mention damages (and not only in a peripheral board, but also in the main board with the central processor). For example, such damages as the result of which MBR cannot contact the computer, or refuses to accept and remember absolutely correct setting changes, or it does not work in mode of measurement of input analog values (currents and voltages), destroys elements in the input and output cir- cuits, and many, many others which are not discovered by the self-diagnostics system. And what can one call a MBR's supposed ability to constantly control even the serviceability of output electromechanical relays other than an advertising gimmick? It would be very interesting for us to learn how is it is possible to control the serviceability of the electromechanical relay all the time without causing its to operate.

Our research has shown that the matter is about the control of a relay coil's continuity which is carried out by letting weak current flow through it, not causing the relay operation. Is it the relay coil but not its contacts that is the most loaded and most unreliable element? Certainly it is not, but it is much easier to organize a useless control of the coil, than the control of the condition of the contacts. Apparently for a new advertising slogan it is absolutely unimportant what exactly is controlled.

1.2. The MBR printed circuit board (PCB) is implemented more and more by using SMD (Surface Mounting Devices) technology; such that, the density of the SMD microcomponents on the board is so high, Fig. 1, that it is absolutely hopeless even to discuss troubleshooting and repairing such a PCB. One can only throw it out and replace it with a new one. Let the reader imagine the approximate cost of the relay REL-316 PCB with the CPU Intel486 type, represented on (Fig. 1).

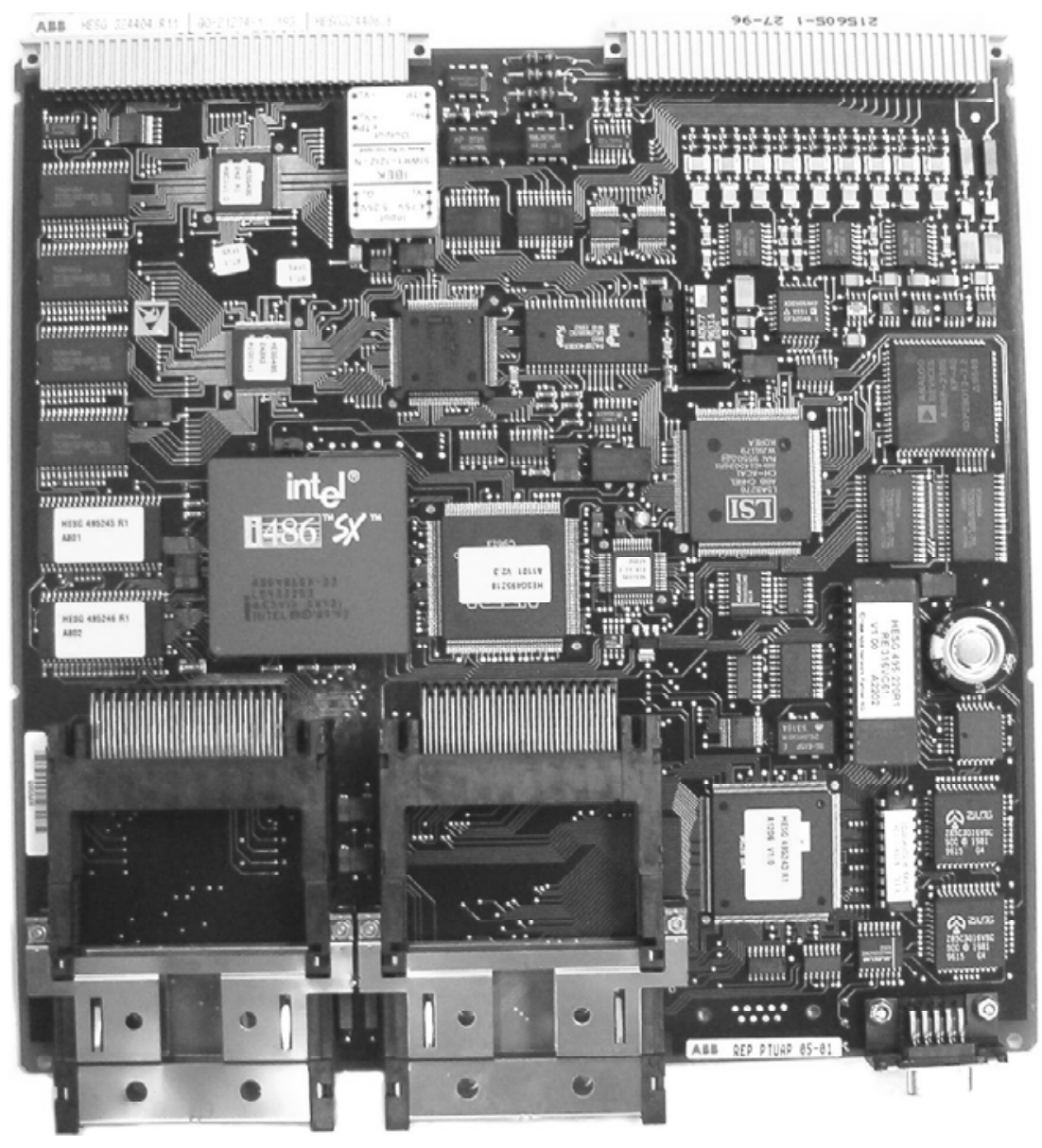

Fig. 1. Main board of the MBR series RE_*316 based on computer chip Intel-486 


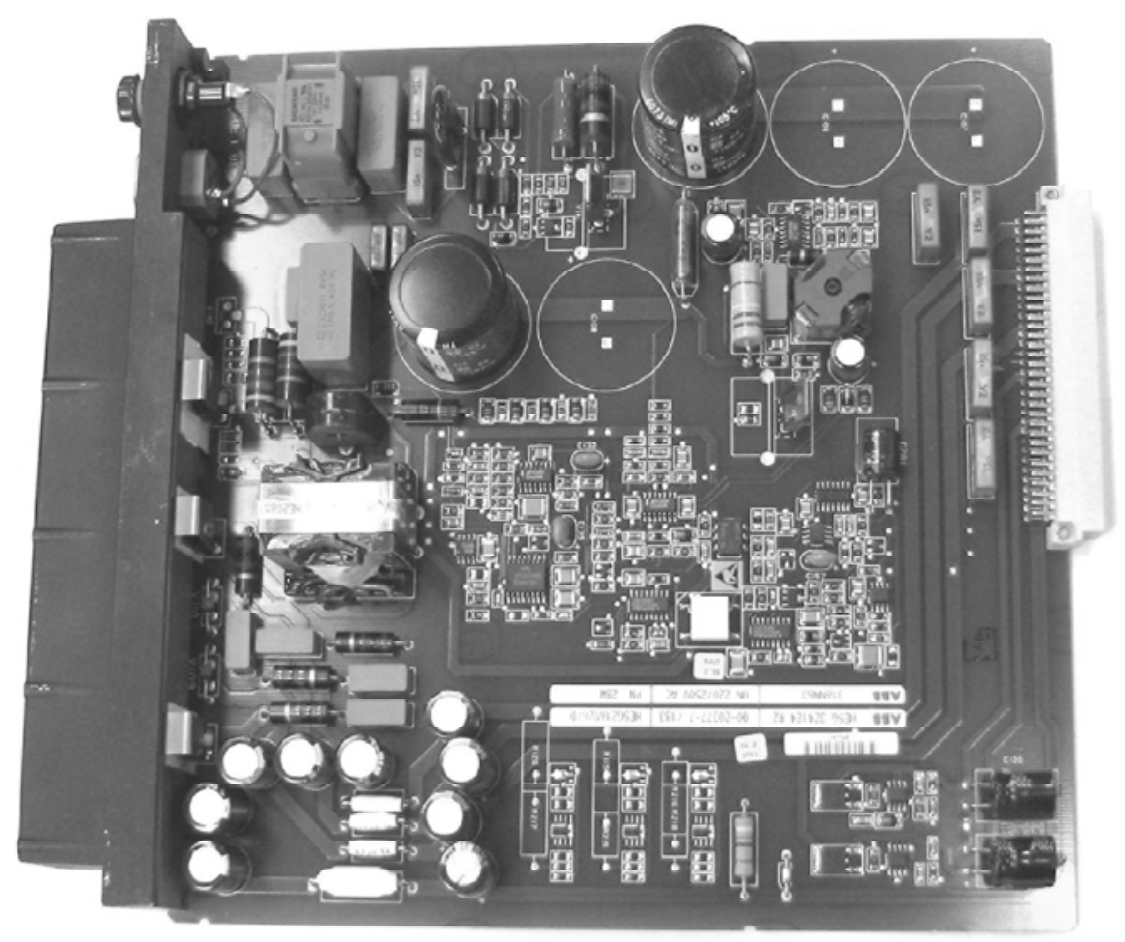

Fig. 2. The PCB of the switching power supply of the MBR, combining SMD microcomponents with large discrete elements of usual installation

Nowadays there is tendency to place SMD microcomponents together with large power elements, electrically connected with each other on one PCB (Fig. 2).

Taking into account the fact that manufacture companies never give the consumer detailed circuit diagrams of the PCBs, searching for malfunctions in them and repairing them are also very difficult. Often one has to throw it out, despite number of large discrete components that are usually found on them. The tendency of increasing of the density installation is peculiar to PCBs on the basis of usual discrete elements.

When the matter concerns power supplies functioning at relatively high voltages and powers (Fig. 3), installations such as these result in a dangerous approach to printed

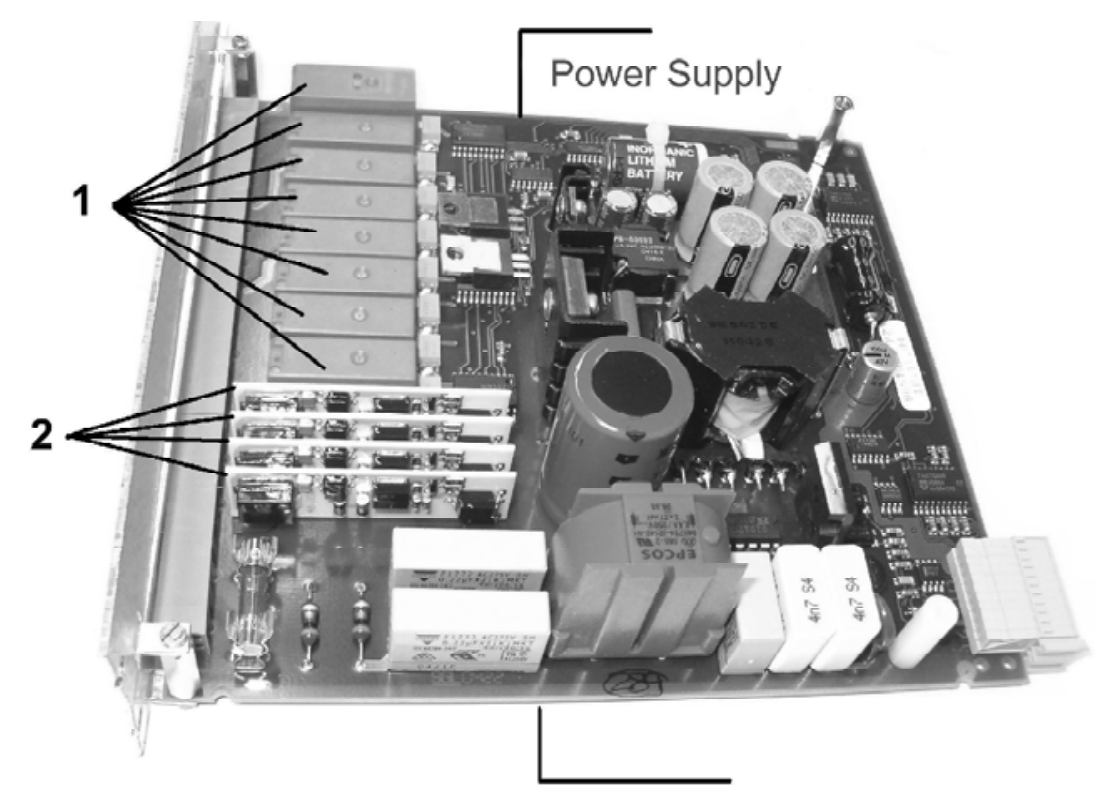

Fig. 3. The board of the MBR uniting different functional units and fully made on electronic elements of usual, but high-density installation 
conductors with different potentials on the board and increase the possibility of electrical breakdown of dusty PCBs with the increase of humidity. In addition, dense installation makes thermal conditions of electronic components work more difficult which leads to a considerable shortening of their operating life. It is not at all simple and cheap to search for malfunctions and repair PCBs due to dense installation such as these and one should take into account the substantial expenditure of time this entails.

1.3. A serious problem is represented by electrolytic capacitors widely used in MBR power supplies. After 710 years of operation in switching high-frequency power supplies even high-quality capacitors produced by wellknown Japanese companies begin to leak, emitting a chemically aggressive electrolyte. Even with this, the power supply functionality continues until adjacent microcomponents are destroyed or copper tracks of printed circuit dissolve. Even the layer of special firm lacquer called «mask» cannot save them (Fig. 4). Nobody would dare guarantee the good condition of the unit even after attempts have been made to rectify the damage and to put such responsible device as MBR into operation again after damages of this kind.

1.4. Only the desire for decreasing the MBR dimensions can explain the fact that almost all the world-leading producers of MBRs use miniature electromagnetic relays for the direct switching of trip coils of high-voltage circuit breakers and to control rather powerful external intermediate relays. As it is shown in [2-4], the technical specifications of a vast majority of such relays fall short of their real operating conditions in the MBR. Naturally, this reduces protection reliability.

1.5. In some types of MBR produced by world-leading companies one finds small connectors (slots) in circuits with voltage $250 \mathrm{~V}$ which are not intended for functioning at such voltages. In order to decrease the risk of electrical breakdown between close outputs of miniature relays and connectors, one sometimes makes special cuts in PCB of MBR between the outputs (Fig. 5).

1.6. Constantly increasing the density of installation worsens the situation with electromagnetic compatibility, especially in the atmosphere of the increased risk of deli-

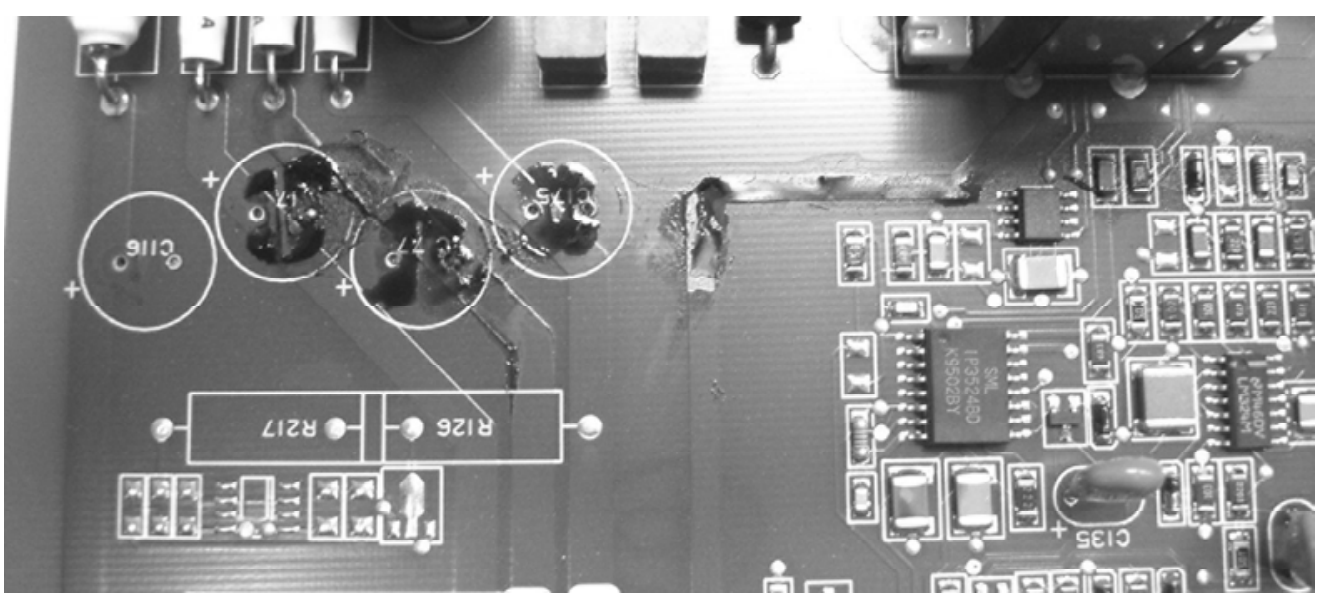

Fig. 4. Fragment of MBR PCB with damages caused by electrolyte leakage from capacitors

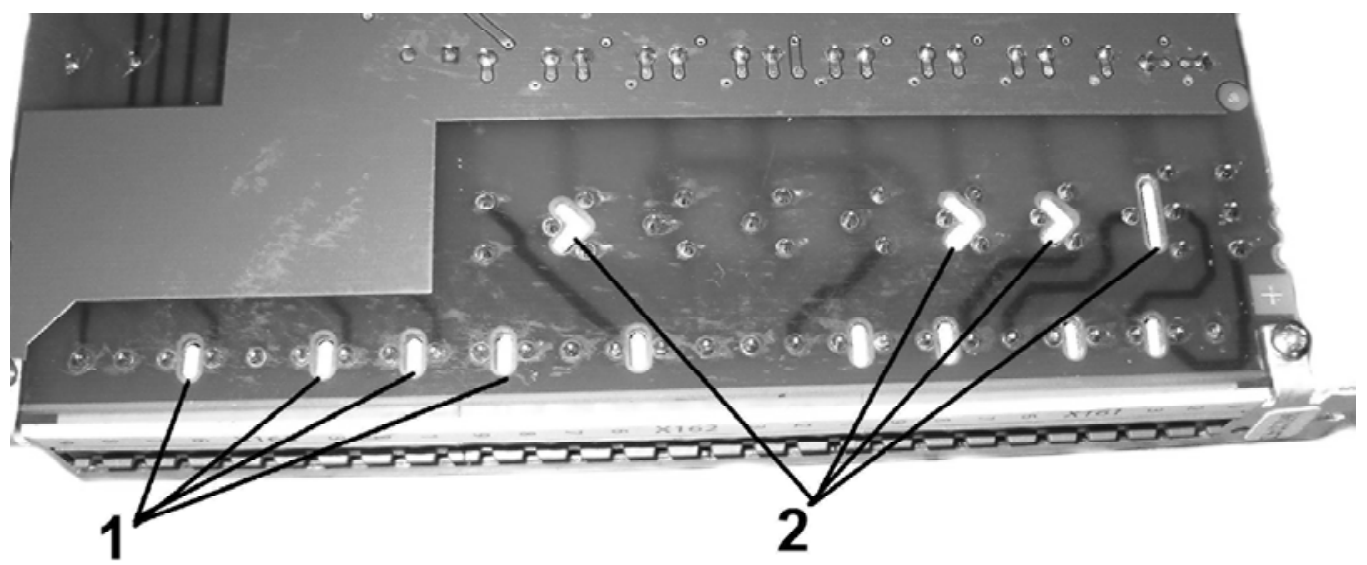

Fig. 5. Fragment of MBR PCB with cuts made between close outputs of small connectors (1) and miniature output relays (2), with the view of preventing of electrical breakdown 

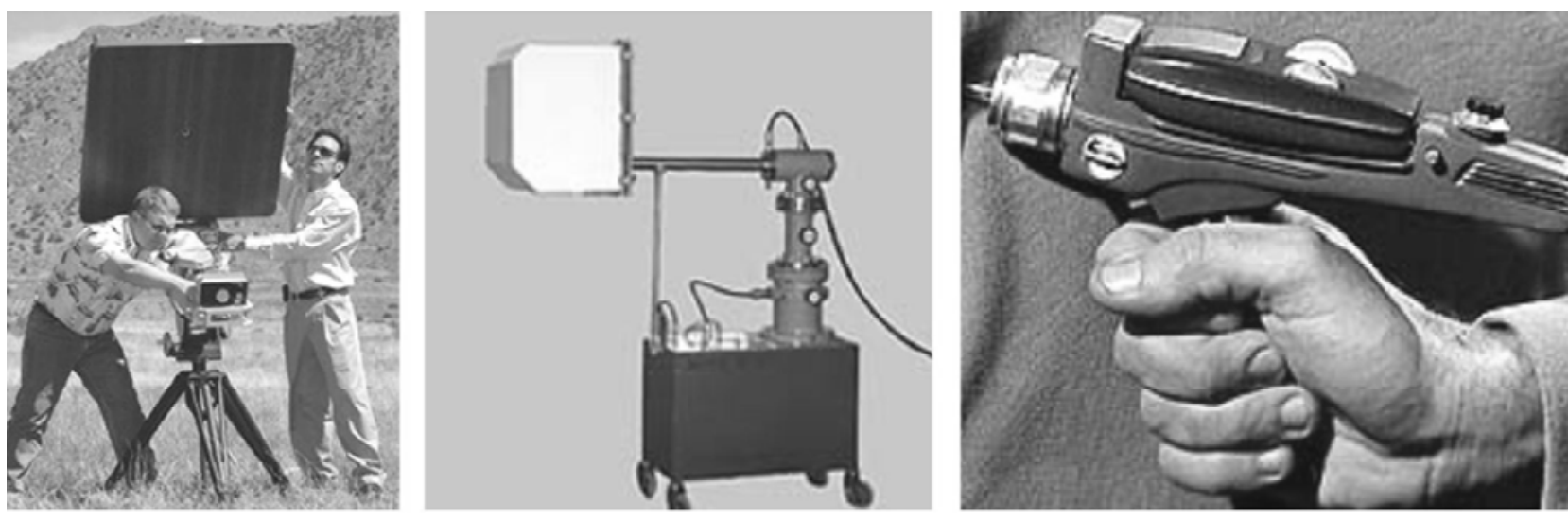

Fig. 6. Special powerful pulse ultrahigh-frequency generators used to impact on electronic equipment

berate remote impact on the MBR by very powerful directional electromagnetic pulses [5]. Special powerful pulse, ultrahigh-frequency generators (Fig. 6) allow disabling existing MBRs instantly from a distance of several tens of meters to half a kilometer even from a driving car, never mind from military target killers like electromagnetic bombs and warheads which anyone can freely buy at arms market today.

1.7. It should be absolutely obvious by now that constantly increasing the concentration of functions of relay protection in one device together with the simultaneous increase of loading factors of electronic components does not at all favour the growth of MBR reliability. In this case only one component serving any general purpose for the whole MBR unit can fail (central microprocessor, memory, power supply, etc.) and this will lead to the false switching off of an important power object or to serious damage because of the non-response of MBR in an emergency situation.

1.8. MBRs are expensive devices and they can be bought, as a rule, at competitive bidding. Not all MBR functional units have equal loading, equal thermal conditions and equal probability of failure, equal service life. Very loaded units like power supplies, input-output boards are most liable to failures such as electrical breakdown or thermal damage. Failures of central processor units are of absolutely a different character and are usually connected not with physical damages, but with problems with the operating program. As a rule, units with input current and voltage transformers almost do not fail. In different models of MBRs of different producers the reliability indices of certain units may differ considerably. However, nowadays it is absolutely impossible to use functional units of MBRs of one type instead of the units with the same purpose of an MBR of other type. Moreover, even the substitution of an MBR of one producer for the MBR of another producer at functional substation causes difficulties due to great variety of forms and dimensions of these devices (Fig. 7).

1.9. Digital (logic) inputs in MBRs of a very widely spread type REL, REC, RET 316 series are implemented as a set of absolutely identical cells which are functionally INHIBIT logic elements (Fig. 8). The input and output of this circuit through the insulation optrons Opt1 and Opt2 are cut into the MBR electrical circuits connected with microprocessor. A signal coming from optron Opt 2 logically simulates (repeats) the presence or lack of input voltage.

The functioning of this circuit may be blocked on a software basis. With this, the blocking signal is sent to the inhibiting input of a cell (Opt1 input) from the microprocessor through corresponding electronic circuits. The problem of this logic cell consists in the input signal high level (220-250 V DC), which should be reduced to the 1,5$2 \mathrm{~V}$ level at which the optron, Opt2, functions. The common

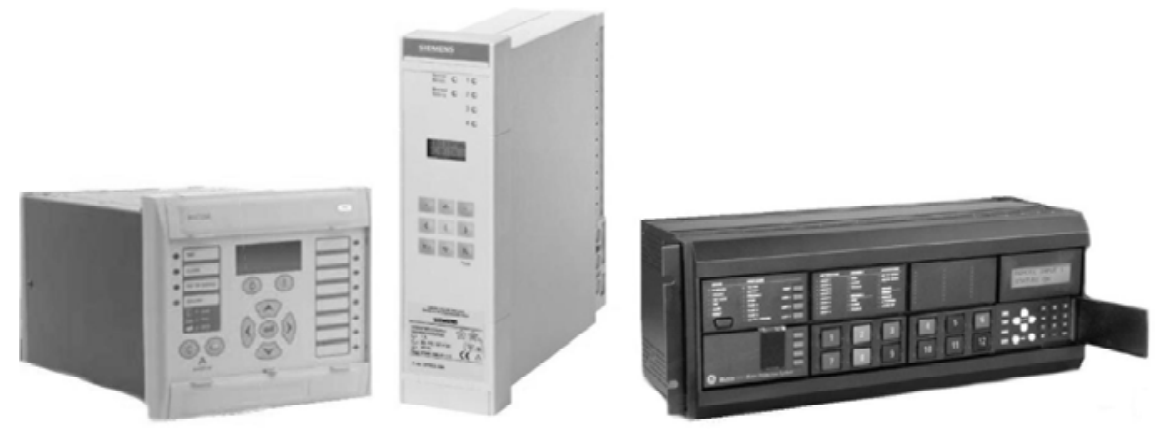

Fig. 7. Modern MBR of world leading producers 

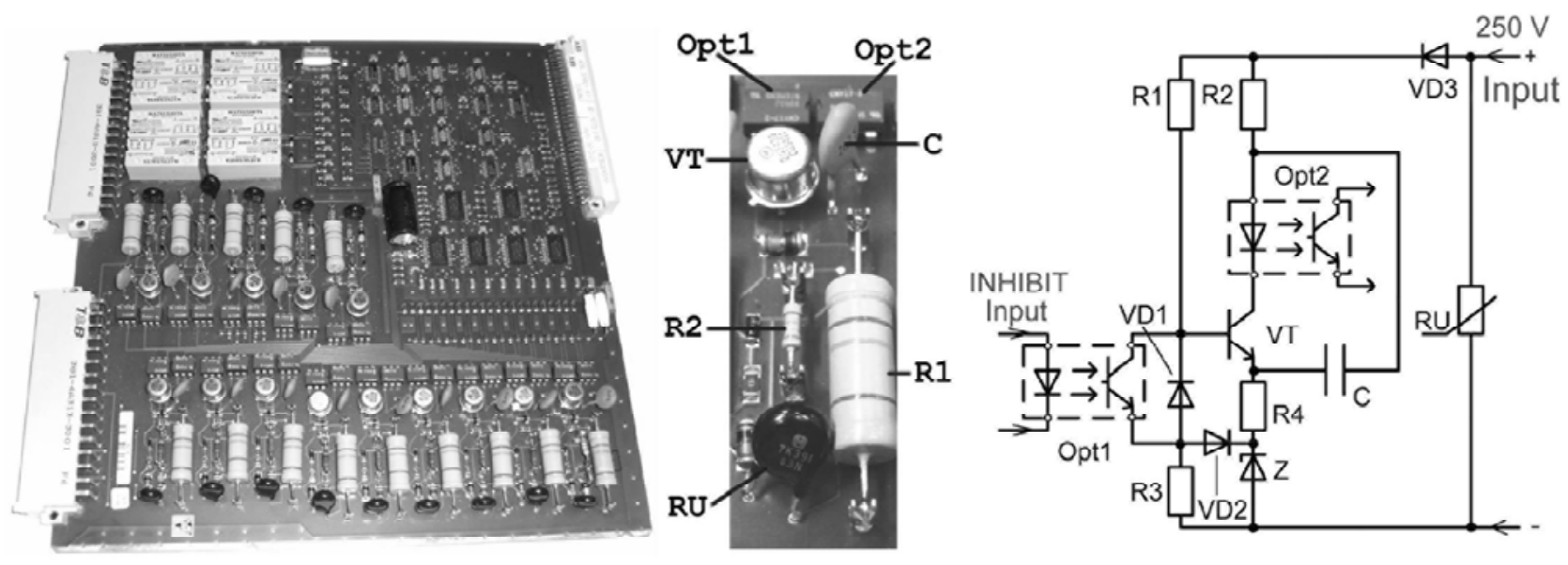

Fig. 8. Digital (logic) inputs of MBR RE_*316 series: PCB, one channel and its circuit schematic

current consumed by the circuit is divided between resistors R1 and R2 into approximately equal parts, this is why they both, in fact, should have had equal power. However two large resistors (like R1), especially with a distance between them necessary for cooling, cannot be placed together on board. That is why the MBR designers decided to give the functions of an element dissipating surplus power to transistor VT which functions not in a key mode (as it is usual in such circuits), but in a booster mode. Surely, in this case resistor $\mathrm{R} 2$ has low power and small dimensions. Really, it is an original decision, but, in practice, this tendency to miniaturization leads to serious problems: often resistor R2 burns out completely and this sometimes results in the burn out of parts of the board and even adjacent elements. The problem lies in transistor VT.

Constantly functioning in the booster mode and dissipating surplus power, transistor VT heats up to $70-80^{\circ} \mathrm{C}$. Unlike a normal resistor, in which the resistance grows insignificantly with increasing temperature, resistance of the direct transition of transistor decreases significantly as a result of operating point shift at the characteristic and amplification factor increases. This leads to collector current increase, i.e., current through resistor R2. When the simultaneous heating of many R1 resistors and VT transistors in ten-fifteen input circuits takes place, the temperature may rise significantly in part of the MBR case (separated by partitions) in which the board of digital inputs is installed. This leads to a further shift of the transistor operating point and a current increase to its collector completes the burn out of resistor R1. In this situation diode, VD, which according to the scheme should stabilize the transistor operating point, appears to have little effect as its temperature and the transistor temperature differ by $50-60$ degrees. Thus, producer's desire for reducing the MBR dimensions using this transistor instead of powerful resistor for dissipating of surplus power has led to the deterioration in MBR reliability. The problem of insufficient reliability of this scheme connected with miniaturization consists not only in the difficulty described above. One more reason of resistor R2 burn out, which was discovered in practice, is poor level of insulation of miniature capacitor C. Partial breakdowns in its inner insulation and an increase of leakage current at a constant voltage $200 \mathrm{~V}$ also leads to resistor R2 fusing. These breakdowns can also happen because of the insufficient efficacy of varistors RU used in the MBR the smallest (for saving room) and, therefore, the most lowpowered of all existent types. Because of their size they are not always able to absorb energy of surge discharge. Additionally, it is not clear what protects what: the varistor protects the electronic components or the electronic components protect the varistor, as the clamping voltage of the varistors $(650 \mathrm{~V})$ installed on the board significantly exceeds the voltage rating of electronic components, for example, $350 \mathrm{~V}$ for transistor VT. With such ratio of parameters, electronic components will fail until varistors are actuated.

1.10. In order to increase the reliability of the MBR power supply one uses, as a rule, direct operational current. However, even using direct operational current does not exclude malfunctions in the accumulator circuits. For example, the supply of the direct current bus bars at the substation is provided only by a charger supplied from the direct current mains. In case of emergency conditions in highvoltage power mains protected by an MBR, the supply of the charger disappears and the MBR looses its power supply at the most crucial moment. Our research [6] has shown that in real operating conditions, MBRs of different types have time to generate a signal for switching the circuit breaker off only if they work in mode of momentary cutoff, i. e., without time delay.

\section{Offered solutions}

2.1. In our opinion, the basic design principle for future MBRs should be similar to modern PCs: hundreds of varieties of containers, motherboards, storage units, and peripheral devices of many different producers perfectly combined with each other such that they are interchangeable and allow upgrading certain units without affecting other 
ones. There is no reason not to apply the same principle to new MBRs. We see the MBR of the future as certain functional modules implemented on the printed circuit boards in a single constructive style (standard) provided with plugin connectors.

We think that one should transfer this principle from the sphere of PCs also into the sphere of software: a basic «relay» prototype of Windows ${ }^{\mathrm{TM}}$ and a set of applications realizing functions of concrete types of protection on a general basis is the most perspective line of software development.

2.2. MBRs should be placed in special metallic boxes (Fig. 9), produced according to a special technology ensuring reliable protection against external electromagnetic radiation over a wide frequency spectrum. Nowadays such boxes are produced by many companies, for example, R. F. Installations, Inc., Universal Shielding Corp., Eldon, Equipto Electronics Corp., European EMC Products Ltd., Amco Engineering, and many others. The boxes should have guides for inserting the printed circuit boards and corresponding connectors for connecting the boards. One such box may contain several different MBRs. Protection relays occupy a very small area of substation or station; therefore the problem of limitation of space occupied by these boxes should not be the prime consideration of new principles of protection devices design. On the contrary we think that the density of installation of PCBs implemented on usual elements should be reduced such as to allow a semiskilled technician to search for malfunctions and repair the device without difficulties. Trends of this kind, but not the abovementioned FUF, should become the criterion of MBR technical level.
2.3. The power of elements versus the dissipating power should be set (according to the author's experience) to exceed the dissipated power by 4-5 times. Only in this case one can ensure relatively low temperatures of force-summing elements and their long service life. Limiting the values of current and voltage of applied electronic components should also be selected with a 4-5 fold reserve. One should select overvoltage protective elements (for example, varistors) with high enough dissipated power (disk diameter not less than $20 \mathrm{~mm}$ ). Acceptable extended operating voltages of these protective elements and clamping voltages should be coordinated with real operating voltages and with a maximum acceptable voltage of applied elements.

2.4. Functional units of future digital protection devices, such as:

- Analog inputs (current and voltage transformers) provided with highly effective interference suppressive filters and electronic elements of primary conversion of signals;

- Logic (digital) inputs provided with high-frequency filters and effective overvoltage protection;

- Power-line filters with multistage overvoltage protection in supply circuit;

- Communication system and data transfer;

- Output relays unit including:

a) Miniature relays with gold contacts for low-current low-voltage signal circuits;

b) Industrial type electromagnetic relays with powerful contacts for controlling intermediate electromagnetic relays of automation systems;

c) High-performance solid-state relays on basis of thyristors or IGBT-transistors with special drivers with optical
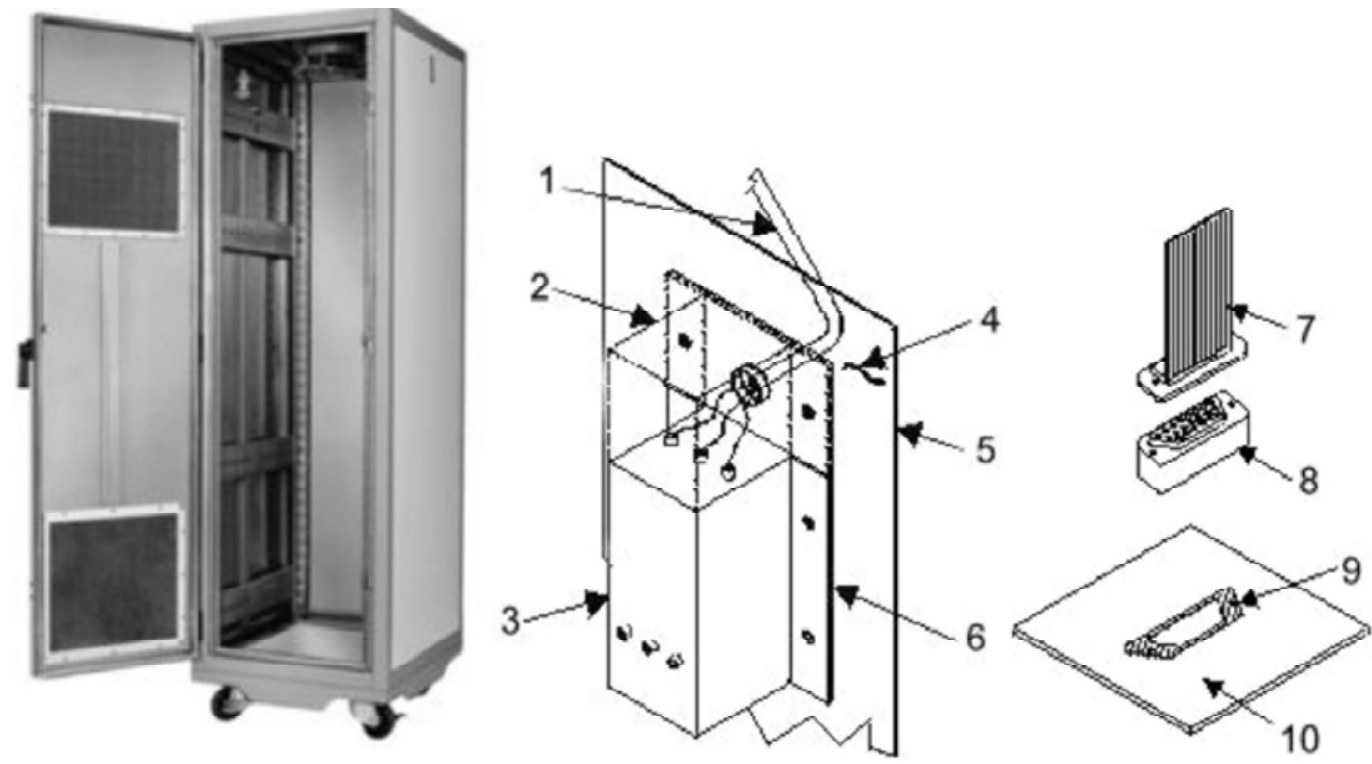

Fig. 9. Special metallic container and elements of filters necessary for enhanced protection against external electromagnetic fields in a wide frequency spectrum:

1 - power shielded cable; 2 - section shielding power cable input and termination; 3 - power line filter with elements of protection against overvoltage; 4 and 5 - internal and external surfaces of the box; 6 and 9 - gaskets of special electroconductive rubber; 7 - signal cable; 8 special high-frequency filter; 10 - container wall 
isolation and with overvoltage protective elements - for switching on of trip coil;

- Power supplies;

- Microprocessor recorders (meters) for recording of emergency modes and actuation of relays and other switching equipment,

should be implemented as separate PCB-modules.

2.5 . The main processor unit with memory and all auxiliary elements should be placed in a separate shielding section and be galvanically insulated from all other units by means of optical coupling.

2.6. One need not change the board of the main processor, connection and data transfer board, board of emergency situations meter implemented on microcomponents of surface mounting. The rest of the boards should be implemented using the usual components and the design of the PCB should be such that it can be searched for malfunctions and repaired. It is obvious that this requirement will be urgent until every MBR board is extremely expensive but board repair remains profitable.

2.7. Though there is a possibility of uniting functions of different types of protection devices placed in one box and to realize them on one general, powerful microprocessor, this possibility, in our opinion, should not be actualized because of the risk of excessive concentration of many protection functions in a single device. Even so, the registration of emergency modes and the activation of all protection devices installed in the box may be implemented on microprocesor and general flash-memory for the whole box. The connection system and data transfer can also be general for all protection devices installed in the box.

2.8. Input transformers of current and voltage (analog input units) are highly reliable elements of MBR and one has not discovered cases of their damage in process of MBR service. This is why their power can be rated for share usage by all MBR devices installed in the box. Units of analog inputs should have functionally completed construction which allows removing the whole unit from general scheme of the MBR and replacing them with blocks of totally other constructions, for example, with optical inputs designed for receiving optical input analog signals from new generation optical transformers of current and voltage.

2.9. Aluminum electrolytic capacitors of power supplies should be placed in a separate block (PCB). This block should be replaced with a new one every 5 years regardless of the capacitors condition.

2.10. Power supplies should be general for the whole box. The power supply should contain two separate independent units: basic and reserve (which begins to function automatically as soon as basic unit fails). In addition, the power supplies should contain small hermetic non-serviced accumulators with charger as is done, for example, in fire alarm systems. It is rather instructive in this case of using this type of accumulator instead of such accumulator electrolytic capacitors of large capacity at voltages not less than 450-500V. In North Caroline University one developed capacitors with accumulated energy which exceeds energy of usual capacitors by 5-7 times [7]. It is also possible to use super capacitors which ensure power of relay protection box during some period of time sufficient for protection actuation in case of failures in centralized power system [6]. Power circuits of every separate module should be disconnected from power circuits of the next module such that damage in one of them cannot affect the functionality of the other.

2.11. Relay protection boxes should have a board-module with high-performance, high-reliable electromechanical elements implemented, for example, on reed switches or hybrid reed switch-semi conductive elements. Such elements as these will ensure high-performance actuation of output protection relays around microprocessors at current big multiplication factors for protection device input, when the mode is definitely determined as emergency, and no other processing of input signal is not needed to determine mode as an emergency. As is shown in author's works [8, 9], simple modules on such elements have high performance (0,8-1,5 ms), which significantly exceeds the highest performance of MBRs (20-40 ms).

2.12. As it is shown above, analysis of MBR condition only by means of imbedded software, as it happens today, is definitely not effective. On the other hand, real selfdiagnostics, including the special sending of standard test signals automatically to analog and digital inputs of an MBR from an external source, and registration of changes in condition of relay and its outputs circuits is impossible without the complete disconnection of relay. In our opinion, the possibility of periodic automatic disconnection of an MBR with further automatic actuation of diagnostic system on active objects of electric-power industry is rather doubtful. Besides, to check certain functions of relay it is often needed changing (or canceling) some protection settings with further return on test completion. Complexity and costs of the system which provides checks such as these will be similar to cost of MBR itself. If we add the inevitable reduction of reliability to this whole complex because of its complication, and also the necessity of periodic calibration of diagnostics system, the hopelessness of this way of development is obvious, at least, in the nearest future. In our opinion, a much more attractive idea is the creation of a portable, mobile universal automatic diagnostic complex controlled by means of an external portable computer and a set of specialized programs for every type of protection, which operating in a half-automatic mode would take 15 30 minutes to effectively test the MBR. In general, a good basis for such diagnostic centers already exists: it is devices produced by companies such as Omicron, Doble and others. It is necessary to provide these devices with multichannel interfaces for the synchronous connection of numerous inputs and outputs of the MBR, and also to develop a set of application programs, which ensure testing different MBR in an automatic mode. We think that with such diagnostic complexes, it makes sense to return to periodic 
check-ups of MBR with economically motivated intervals.

\section{Conclusion}

The principles of MBR construction that have been discussed will allow, in our opinion, to increase its reliability, flexibility and usability. One will have opportunity to modernize protection with minimum costs. If some MBR units functioned unsatisfactorily, one can easily replace them with units of another producer. Having decided to use new generation microprocessor, one should not replace the whole device, including input circuits, power supplies, filters, etc., rather only one or two PCBs need be changed. Introducing the use of optical transformers of current and voltage will involve changing only one PCB of analog inputs, but not the whole protection device as one has to do today. Likewise, one could change and modernize protection software. All this will lead to the rise of new companies in the market, which are specialized in production of separate functional blocks and separate application programs, increase of competition and, finally, to rash quality improvement of MBR with simultaneous cost reduction.

The author understands that he has not considered all aspects of the problem and has not formulated all the principles of construction of future MBRs and that is why he invites all interested specialists to discuss this topic.

\section{References}

1. Gurevich V. Electric Relays. Principles and Applications / Gurevich V. - Boca Raton, New-York, London : Taylor \& Francis Group, 2005. -671 p.

2. Gurevich V. Nonconformance in Electromechanical
Output Relays of Microprocessor-Based Protection Devices Under Actual Operating Conditions / Gurevich V. // Electrical Engineering and Electromechanics. -2006. - No 1. - P. 12-16.

3. Gurevich V. Peculiarities of the Relays Intended for Operating Trip Coils of the High-Voltage Circuit Breakers / Gurevich V.// Електротехника та Електроенергетика. - 2009. - № 2. - С. 15-21.

4. Gurevich V. Dealing with Problems in Output Relays Used in Microprocessor-Based Protection Devices / Gurevich V. // Electricity Today. Transmission and Distribution. - 2007. - Part I, in No 1 (Vol.19); Part II, in No 2 (Vol. 19). - P. 22-24.

5. Gurevich V. Electromagnetic Terrorism: New Hazards / Gurevich V. // Electrical Engineering and Electromechanics. - 2005. - No 4. - P. 81-83.

6. Gurevich V. A Problem of Power Supply of Microprocessor-Based Protective Relays in Emergency Mode/ Gurevich V. // Electricity Today. Transmission and Distribution. - 2006. - No 8 (Vol. 18). - P. 32-35.

7. Capacitors Hold Promise of Increase in Energy Storage Capability. - RF Design, Jul.25, 2007.

8. Gurevich V. Hybrid Reed - Solid-State Devices are a New Generation of Protective Relays / Gurevich V. // Електротехника та Електроенергетика. -2007. - №1. -C. 61-66.

9. Gurevich V. Very Simple High-Speed Overcurrent Protection Relay / Gurevich V. // Electrical Engineering and Electromechanics. - 2007. - No 1. - P. 13-16.

Поступила в редакцию 12.11 .07 г.

Гуревич В. Микропроцессорные устройства релейной защиты: настоящее и будущее.

В статье представлен анализ основных конструктивных недостатков современных микропроцессорных устройств релейной защиты (МУРЗ) и предлагаются основные принципы построения МУРЗ, которые могут использоваться при создании новых устройств.

микропроцессорные устройства защиты, повреждения реле, надежность релейной защиты

Гуревич В. Мікропроцесорні пристрої релейного захисту: сьогодення й майбутнє.

У статті представлений аналіз основних конструктивних недоліків сучасних мікропроцесорних пристроїв релейного захисту (МПРЗ) і пропонуються основні принципи побудови МПРЗ, які можуть використовуватися при створенні нових пристроїв.

мікропроцесорні пристрої захисту, ушкодження реле, надійність релейного захисту 